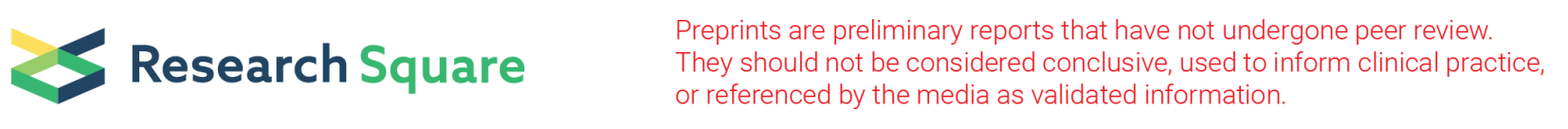

\title{
Influence of Dietary Genistein and Polyunsaturated Fatty Acids on Lipid Peroxidation, and Fatty Acid Composition of Meat in Quail Exposed to Heat Stress
}

\author{
Cemal Orhan ( $\nabla$ corhan@firat.edu.tr) \\ Firat Universitesi \\ Nurhan Sahin \\ Firat University: Firat Universitesi \\ Kazim Sahin \\ Firat University: Firat Universitesi \\ Osman Kucuk \\ Erciyes Üniversitesi: Erciyes Universitesi
}

\section{Research Article}

Keywords: Heat stress, Genistein, Polyunsaturated fatty acids, Lipid oxidation, Quail

Posted Date: July 20th, 2021

DOI: https://doi.org/10.21203/rs.3.rs-688325/v1

License: (c) (i) This work is licensed under a Creative Commons Attribution 4.0 International License. Read Full License 


\section{Abstract}

This experiment was conducted to investigate the effects of polyunsaturated fatty acids (PUFA) and genistein on performance and meat fatty acid profiles in quail exposed to heat stress. A total of 360 Japanese quail were divided into 12 groups in a 2x2x3 factorial design; each group comprised 30 quail with five replicates and were kept either at $22 \pm 2^{\circ} \mathrm{C}$ for $24 \mathrm{~h} / \mathrm{d}$ (Thermoneutral,TN) and $34 \pm 2^{\circ} \mathrm{C}$ for $8 \mathrm{~h} / \mathrm{d}(08: 00$ to $17: 00 \mathrm{~h})$ followed by $22^{\circ} \mathrm{C}$ for $16 \mathrm{~h}$ (Heat Stress,HS) conditions. The diet contained either two levels of PUFA at 15 or $45 \%$ of total fat or three levels of genistein at 0,400 , or $800 \mathrm{mg} / \mathrm{kg}$. Bodyweight gain, feed intake, and feed efficiency were lower $(p \geq 0.01)$ for quail reared under heat stress and fed low PUFA. Increasing dietary genistein in a linear manner improved the productive performance $(p<0.001)$. Heat stress caused increases in serum and thigh meat malondialdehyde (MDA) concentrations and decreases in genistein, vitamin E and A concentrations in serum and thigh meat $(p<0.001)$. High PUFA (PUFA45) in diet of quail caused greater 18:2, 18:3 ALA, EPA, DHA, $\mathrm{n}-6$, and $\mathrm{n}-3$ PUFA as well as total PUFA and total USFA percentages $(p<0.001)$ in thigh muscle, some of which decreased with heat stress $(p \geq 0.006)$ with no regards to genistein supplementation. This study revealed that genistein with greater doses along with greater PUFA inclusion to the diet of quail reared under heat stress is recommended for alleviating adverse effects of heat stress and for yielding healthier meat for human consumption.

\section{Introduction}

Heat stress (HS) is one of the major concerns in poultry rearing. High surrounding temperature negatively influences the live performance, product quality, health status, survival, and general welfare of the poultry (Alfthan et al. 2015; Attia et al. 2016; Goel, 2021; Nawab et al. 2018). Management strategies including ventilation, more appropriate floor space (Ratriyanto and Prastowo, 2019) as well as the usage of specific nutrients in the diet such as probiotics, prebiotics (Li et al. 2020; Sohail et al. 2011), vitamins and minerals (Sahin and Kucuk, 2003; Sahin et al. 2009; El-Kholy et al. 2017; Orhan et al. 2019) in helping alleviate the adverse effects of heat stress has been widely appreciated.

Supplementing fatty acids (FA) to the diet of poultry enhances the growth, production performance, and health of poultry (Alagawany et al. 2019; Shang et al. 2004). Moreover, supplementing polyunsaturated fatty acids (PUFA) to the poultry diet has been reported to increase the deposition of PUFA in poultry products, and consequently, upon consumption, offer an important source of PUFA for humans (Konieczka et al. 2017; Wu et al. 2019). Consumption required amounts of PUFA as eicosapentaenoic acid (EPA; 20:5n-3), docosahexaenoic acid (DHA; 22:6n-3), and alpha-linolenic acid (ALA; 18:3n-3) is linked to the prevention of many chronic diseases, including cardiovascular problems and cancer (Manson et al. 2019; Mika et al. 2020).

Genistein, as the main soy isoflavonoid, plays an important role against oxidative stress and certain diseases such as diabetes and cancer (Gupta et al. 2015; Sanaei et al. 2018; Ustundag et al. 2007). It has also been reported that dietary supplementation of genistein to quail reared under HS showed a protective effect against oxidative stress (Onderci et al. 2004). There is no study conducted in the literature using a combination of PUFA and genistein in poultry under heat stress. Therefore, the objective of the present work was to investigate the effects of dietary PUFA and genistein supplementation on productive performance, serum and meat genistein concentrations, and antioxidant status, as well as meat fatty acid profiles in quail reared under heat stress.

\section{Materials And Methods}

\section{Animals, diet, and experimental design}

The experiment was conducted following animal welfare regulations at the Veterinary Control and Research Institute of Elazig, Turkey, with all procedures approved by the Institutional Animal Care and Use Committee. A total of 360 ten-day-old Japanese quail (Coturnix coturnix japonica) were randomly divided into 12 groups in a 2x2x3 factorial design (2 environmental temperatures $\times 2$ levels of dietary PUFA $\times 3$ levels of dietary genistein), with each group containing 30 birds subdivided into five replicates with six birds each. The birds were kept in a temperature-controlled room at either $22 \pm 2^{\circ} \mathrm{C}$ for $24 \mathrm{~h} / \mathrm{d}$ (thermoneutral, $\mathrm{TN}$ ) or $34 \pm 2^{\circ} \mathrm{C}$ for $8 \mathrm{~h} / \mathrm{d}\left(08: 00\right.$ to $17: 00 \mathrm{~h}$ ) followed by $22^{\circ} \mathrm{C}$ for $16 \mathrm{~h}$ (heat stress, HS) during the experimental period (from d 10 to $\mathrm{d} 45$ ). Animals were fed a basal diet (Table 1) or basal diet supplemented with two PUFA levels at 15 or $45 \%$ of total fat ( $\mathrm{g} / 100 \mathrm{gr}$ fat) or three genistein levels at 0,400 , or $800 \mathrm{mg} / \mathrm{kg}$. The basal diet contained $9 \%$ added fat source as either tallow only or as a combination of tallow (ELET Inc. Elazig, Turkey), linseed oil, and fish oil (Oz-Gida Inc. Elazig, Turkey). The PUFA levels as 15 or $45 \%$ (g/g fat) for PUFA15 and PUFA45 in the diets were formulated as reported by Cortinas et al. (2004). The fatty acid compositions of the PUFA15 and PUFA45 of the diets are presented in Table 2 . Genistein contained $98 \%$ aglycone form genistein and $2 \%$ starches as a carrier (Bonistein, DSM Nutritional Products, Istanbul, Turkey). Feed and water were offered ad libitum throughout the experiment.

\section{Samples and data collection}

Cumulative feed intakes and body weight gains were recorded weekly. Weight gains and feed conversion ratio (FCR: feed intake, g: weighed gained, g) was then calculated.

At the end of the study, a total of 120 animals ( 10 from each group and 2 from each subgroup) were randomly chosen and slaughtered to take blood and left thigh meat samples. Blood samples were taken into gel biochemistry tubes (Standard plus \& Medical Co. Ltd. Germany) and centrifuged in a cooled centrifuge (Universal 320R, Hettich, Tuttlingen, Germany) at $5000 \mathrm{rpm}$ for 10 minutes at $4{ }^{\circ} \mathrm{C}$, and serum samples were obtained. All samples were stored at $-70^{\circ} \mathrm{C}$ in the deep freezer (Hettich, Tuttlingen, Germany) until analyzed. 
For the analysis of fatty acids, samples were extracted according to the method reported by Hara and Radin (1978). $1 \mathrm{~g}$ feed and left thigh samples were homogenized with $5 \mathrm{ml}$ of hexane-isopropanol $(3: 2, \mathrm{v}: \mathrm{v})$, centrifuged and the supernatant was taken. Fatty acid methyl esters were prepared in the hexane/isopropanol phase, and $5 \mathrm{ml}$ of $2 \%$ methanolic sulfuric acid was added, mixed, and left to methylated in a $50{ }^{\circ} \mathrm{C}$ oven (Memmert, Germany). Then $5 \mathrm{ml}$ of $5 \%$ sodium chloride ( $\mathrm{NaCl}$, Merck, Darmstadt, Germany) was added. Fatty acid methyl esters were extracted with hexane, and the hexane phase was treated with $5 \mathrm{ml}$ of $2 \%$ potassium bicarbonate $\left(\mathrm{KHCO}_{3}\right.$, Merck, Darmstadt, Germany). The supernatant was taken and evaporated. The residue was dissolved with $1 \mathrm{ml}$ of hexane and analyzed by Gas Chromatography (Shimadzu GC 17, Japan). The column temperature program was set from $120{ }^{\circ} \mathrm{C}$ to $220^{\circ} \mathrm{C}$. Fatty acid peaks were recorded and integrated using a Hewlett-Packard 3396 integrator. Calculations were made using the GC Solution (LabSolution GC solution 2.3) package program. Fatty acids of muscle were reported as a percentage (\%).

\section{Analysis of malondialdehyde, vitamins, and genistein by HPLC}

Tissue and serum MDA, vitamin and genistein levels were performed by using an HPLC (Shimadzu, Japan) with ultraviolet (UV) detector (SPD-20A), pump (LC-20AD), automatic sampling device (SIL-20A), column oven (CTO-10ASVP) units and C18 column (ODS-3, 5 $\mu \mathrm{m}, 4.6 \times 250 \mathrm{~mm}$, Inertsil, GL Sciences, Japan). LC Solution (LabSolution LCL solution Release 1.21) package program was used.

The malondialdehyde (MDA) and vitamin C levels of serum and thigh meat samples were determined as reported previously (Sahin et al. 2016). Briefly, $300 \mu \mathrm{l} 0.5 \mathrm{M}$ perchloric acid $\left(\mathrm{HClO}_{4}\right.$, Riedel, Seelze, Germany) was added to the $400 \mu \mathrm{l}$ serum sample, centrifuged, and the supernatant was taken. For tissue analyses, $0.5 \mathrm{~g}$ of thigh meat samples were homogenized with $1 \mathrm{ml}$ ultra-pure water, $100 \mu \mathrm{l}$ butylhydroxytoluene (500 $\mu \mathrm{g} / \mathrm{ml} ; 2,6-\mathrm{di}$ t-butyl-p-cresol, $\mathrm{BHT}$ ) and $1 \mathrm{ml} 0.5 \mathrm{M} \mathrm{HClO}_{4}$. Then, samples were centrifuged at $5000 \mathrm{rpm}$ and $4{ }^{\circ} \mathrm{C}$ for 10 minutes, and the supernatant was taken for $\mathrm{HPLC}$ analyses. $\mathrm{HPLC}$ analysis conditions included column oven temperature as $30^{\circ} \mathrm{C}$, mobile phase, $30 \mathrm{mM} \mathrm{KH}_{2} \mathrm{PO}_{4}$ and methanol (82.5: 17.5, v/v, pH 3.6), flow rate 1 $\mathrm{ml} / \mathrm{min}$, and wavelength $250 \mathrm{~nm}$.

To detect serum and tissue fat-soluble vitamins A and E levels, samples were analyzed as described by Barim and Karatepe (2010). Briefly, $500 \mu \mathrm{l}$ of extraction solution was added to the $300 \mu \mathrm{l}$ serum sample to precipitate its proteins and extracted with $300 \mu$ l of n-hexane (Riedel, Seelze, Germany) three times and hexane phases were evaporated. The residue was dissolved with methanol. For tissue analyses, $2 \mathrm{ml}$ of ultrapure water and $200 \mu \mathrm{l}$ of BHT (500 $\mu \mathrm{g} / \mathrm{ml}$ ) were added to the $0.5 \mathrm{gr}$ sample and homogenized. Then, $3 \mathrm{ml}$ of extraction solution was added, mixed, and $500 \mu \mathrm{l}$ of $\mathrm{n}$-hexane was added and centrifuged at $5000 \mathrm{rpm}$ at $4{ }^{\circ} \mathrm{C}$ for 10 minutes, and the upper hexane phase was removed. The extraction with hexane was repeated three times. The residue was dissolved with $200 \mu \mathrm{l}$ of methanol. Analysis conditions; column oven temperature was set as $40^{\circ} \mathrm{C}$, mobile phase flow rate $1 \mathrm{ml} / \mathrm{min}$, and wavelengths $326 \mathrm{~nm}$ for vitamin A, and $296 \mathrm{~nm}$ for vitamin $\mathrm{E}$.

Genistein concentrations in serum and tissue samples were determined as defined previously with minor modifications (D'Souza et al. 2005; Tacyildiz et al. 2010). $300 \mu$ l of $0.2 \mathrm{M}$ sodium acetate $\left(\mathrm{pH} 5.0, \mathrm{C}_{2} \mathrm{H}_{3} \mathrm{NaO}_{2}\right.$, Sigma-Aldrich, St. Louis, MO) containing 3500 units of $\beta$-glucorinidase enzyme (Sigma Chemical, St. Louis, MO) was added to $300 \mu \mathrm{l}$ serum sample and $0.5 \mathrm{~g}$ tissue sample and incubated for $6 \mathrm{~h}$. Then, $4400 \mu \mathrm{l}$ of $80 \%$ methanol was added, mixed, and sonicated. The samples were centrifuged and supernatant was taken and evaporated. The residue was dissolved in methanol. Genistein levels were measured by a linear gradient using the reverse-phase separation technique on the HPLC device. Mobile phases forming the linear gradient; A mixture of $0.1 \%$ acetic acid (Merck, Germany), $5 \%$ acetonitrile and $94.9 \%$ ultrapure water, A mobile phase, $0.1 \%$ acetic acid, and $99.9 \%$ acetonitrile mixture was prepared as mobile phase B. Linear gradient applied during measurement; Initially, it was $84 \%$ A mobile phase and $16 \%$ B mobile phase, and until the 15 th minute, the A mobile phase was adjusted to $30 \%$ and the $B$ mobile phase was $70 \%$, and continued at these rates until the 18 th minute. The analysis was continued until 25 minutes by setting the mobile phase ratios to be A $84 \%$ and B $16 \%$ at 20 minutes. Analysis conditions; column oven temperature was set as $40^{\circ} \mathrm{C}$, mobile phase flow rate $1 \mathrm{ml} / \mathrm{min}$, and wavelength $260 \mathrm{~nm}$.

\section{Statistical analysis}

Quail were assigned randomly to one of 12 treatments in a $2 \times 3 \times 2$ factorial arrangement of 2 environmental temperatures (TN vs. HS), 2 dietary PUFA levels ( 15 vs. $45 \%$ of total fat), and 3 genistein levels $(0,400$, and $800 \mathrm{mg} / \mathrm{kg}$ ). Analysis of variance was conducted using the PROC MIXED (SAS, 2004) in a complete randomized design. The linear model to test the effects of treatments on response variables was as follows:

$Y_{i j k l}=m+E T_{i}+G N_{j}+P U F A_{k}+(E T * G N)_{i j}+(E T * P U F A)_{i k}+(G N * P U F A)_{j k}+(E T * G N * P U F A)_{i j k}+e_{i j k l}$

where $\mathrm{Y}_{\mathrm{ijkl}}=$ response variable, $\mathrm{m}=$ population mean, $\mathrm{ET}_{\mathrm{i}}=$ environmental temperature $(\mathrm{i}=\mathrm{TN}$ and $\mathrm{HS}), \mathrm{PUFA} \mathrm{k}_{\mathrm{k}}=\mathrm{PUFA}$ level $(\mathrm{i}=15$ and $45 \%), \mathrm{GN}_{\mathrm{j}}=$ genistein level $(0,400$, and $800 \mathrm{mg} / \mathrm{kg})$, and $\mathrm{e}_{\mathrm{ijkl}}=$ residual error, $N(0,1)$.

Linear and quadratic responses to genistein levels were attained using the polynomial contrast option. The linear model included the time effect and its relevant interaction as repeated measures for the performance variable. Data were reported as mean \pm SEM. A probability value less than 0.05 was considered significant.

\section{Results}

\section{Performance}

As designed, initial BW was similar ( $p \geq 0.08$; Table 3 ) among quail groups reared under TN or HS and supplemented with various levels of PUFA or genistein levels. However, final BW, BW gain, cumulative feed intake, and FCR were greater $(p<0.001)$ for quail reared under TN compared with those 
reared under HS. Adding greater amount of PUFA (PUFA45) to the diet of quail resulted in lower productive performance measured as final BW, BW gain, cumulative feed intake and FCR $(p \geq 0.01)$, whereas higher amounts of genistein caused greater final BW, weight gains, and FCR ( $p<0.001)$. Increases in dietary genistein levels resulted in a lower productive performance in quail reared under HS compared with those of quail reared at TN $(p \geq 0.006$, interaction). In addition, increases in dietary genistein levels resulted in a greater productive performance, except feed intake $(p=0.11)$ in quail supplemented with low PUFA compared with those of quail supplemented with high PUFA $(p<0.001$, interaction). Increased genistein levels in the diet caused positive linear responses in final BW, BW gain, and FCR in quail $(p<0.001)$. There were no three-way interactions detected $(p \geq 0.29)$ for environmental temperature, PUFA and genistein supplementations in quail for productive performances except initial BW $(p<0.04)$.

\section{Thigh muscle fatty acid profile}

The quail reared under HS, compared with those of reared under TN, had greater 15:0, 16:0, 17:0, 18:0 and SFA percentages ( $p \geq 0.006$; Table 4$)$ along with lower 14:0, C16:1n-9, C18:1n-9, 18:2, 18:3 (ALA), 20:5 (EPA), 22:4, 22:6 (DHA), total PUFA, total MUFA, and total USFA as well as lower n-6 and n-3 PUFA percentages together with lower $n-6$ to $n-3$ PUFA ratios $(p \geq 0.003)$ in their thigh muscles. More PUFA (PUFA45) in the diet of quail caused greater 18:2, 18:3, 20:1, EPA, DHA, 24:1, n-6 and n-3 PUFA as well as total PUFA and total USFA percentages $(p<0.001)$ along with lower 14:0, 14:1, 15:0, 16:0, C16:1n-9, C16:1n-7, 17:0, C18:1n-9, C18:1n-7, 18:4, 20:0, 20:1, 20:4, total MUFA and total SFA percentages together with lower $n-6$ to $n-3$ PUFA ratios ( $p \geq 0.02)$ in the thigh muscles. Adding genistein to the quail diet did not influence the FA profiles of muscles $(p \geq 0.09)$. Thigh muscle concentrations of $16: 0$ increased with $400 \mathrm{mg} / \mathrm{kg}$ genistein but decreased again with further increases in genistein at $800 \mathrm{mg} / \mathrm{kg}(p \geq 0.03$; quadratic effect).

Thigh muscle concentrations of 16:0 and total SFA were greater in heat-stressed quail and stayed greater with the supplementation of lower PUFA (PUFA15) ( $p<0.001$; ET x PUFA interaction). However, thigh muscle concentrations of 18:0 were greater in heat-stressed quail and stayed greater with the supplementation of greater PUFA (PUFA45) ( $p<0.001$; ET x PUFA interaction). Quail reared under HS had lower thigh muscle concentrations of 18:2, ALA, EPA, 22:4, total PUFA, total USFA, total n-6 PUFA, and total n-3 PUFA when supplemented with greater PUFA (PUFA45) ( $p \geq 0.013$; ET $x$ PUFA interaction). In addition, the ratios of $n-6$ to $n-3$ were lower in quail reared in HS and stayed even lower with greater PUFA supplementation (PUFA15) ( $p<0.008$; ET $x$ PUFA interaction). Other two-way (PUFA x GN) or three-way interactions (ET x PUFA x GN) were not significant $(p \otimes 0.05)$.,

\section{Serum MDA, genistein, and vitamin concentrations}

Quail reared under HS had greater $(p<0.001)$ serum MDA concentration but lower serum genistein, vitamin $\mathrm{C}$, vitamin $\mathrm{E}$, and vitamin A concentrations compared with those of quail reared under TN $(p<0.001$; Table 5$)$. The presence of greater PUFA (PUFA45) in the diet of quail resulted in greater concentrations of MDA $(p<0.001)$ but lower genistein serum concentrations $(p<0.04)$ with no changes in serum concentrations of vitamin $C$, vitamin $\mathrm{E}$, and vitamin $\mathrm{A}(p \geq 0.19)$. Increasing genistein supplementation to the diet of quail linearly decreased serum MDA ( $p<0.001)$ while linearly increased serum genistein concentrations $(p<0.001)$.

Serum MDA concentrations were greater in quail reared under HS when greater PUFA (PUFA45) was included in the diet ( $p<0.001$; ET $x$ PUFA interaction). Similarly, serum MDA concentrations were greater in quail reared under HS, but supplementing the increasing genistein levels resulted in linear decreases in serum MDA concentrations in quail reared under HS ( $<<0.001$; ET x GN interaction). Heat stress caused decreases in serum genistein concentrations, but supplementing increasing genistein levels to the quail diet resulted in linear increases in the serum of genistein concentrations $(p<0.001$; ET $x \mathrm{GN}$ interaction) in quail reared under HS. Serum MDA concentrations increased with PUFA45 supplementation. However, increasing genistein supplementation linearly decreased serum MDA concentrations in quail supplemented greater PUFA ( $p<0.001$; PUFA x GN interaction). There were no three-way interactions detected $(p \geq 0.08)$ for environmental temperature, PUFA, and genistein supplementation in quail for serum MDA, genistein, and vitamin concentrations.

\section{Thigh muscle MDA, genistein, and vitamin concentrations}

Heat stress caused increases in MDA but decreases in genistein, vitamin E, and vitamin A concentration in thigh muscles ( $p<0.001$; Table 6$)$. Greater PUFA (PUFA45) supplementation to the diet of quail resulted in greater thigh muscle MDA concentrations $(p<0.001)$. However, increasing genistein supplementation caused linear decreases in thigh muscle MDA but linear increases in genistein concentrations $(p<0.001)$. In response to increasing genistein supplementation, the reduction in thigh muscle MDA concentration was greater, and the rate of increase in thigh muscle genistein concentration was less for quail reared under HS than those reared under TN $(p<0.001$; PUFA x GN interaction). There were no other two-way interactions detected ( $p \geq$ $0.15)$ for ET $x$ PUFA or PUFA $x$ GN in quail for thigh muscle MDA, genistein, and vitamin concentrations. In addition, there were no three-way interactions detected $(p \geq 0.37)$ for environmental temperature, PUFA, and genistein supplementations in quail for thigh muscle MDA, genistein, and vitamin concentrations.

\section{Discussion}

The negative impact of heat stress manifested itself in reducing feed intake and weight gains along with depressed feed efficiency in quail of the present work. These results are parallel to the findings of Roushdy et al. (2020), who reported reduced feed intake, weight gain, and feed conversion ratios in broiler chickens exposed to 4 or $6 \mathrm{~h}$ of heat stress $\left(40^{\circ} \mathrm{C}\right)$ per day. Orhan et al. (2020) also reported that laying quail exposed to $8 \mathrm{~h}$ of high ambient temperature $\left(34^{\circ} \mathrm{C}\right)$ per day consumed less feed and had lower apparent total tract digestibility of DM, OM, and crude protein. Depressed digestibility of nutrients occurs due to intestinal injury with reduced heights of the villus along with widening crypt depths of the intestine in broilers (He et al. 2018). Song et al. (2014) also stated that broilers exposed to high environmental temperature had intestinal ischemia and reduced intestinal integrity, leading to lower digestibility. However, Habashy et al. (2017) found that broiler chicks reared under high ambient temperature $\left(35^{\circ} \mathrm{C}\right)$ consumed less protein and fat with no changes in ileal digestibility of these nutrients. 
Fat supplementation to the diet of broilers under heat stress is a strategic way to reduce the adverse effects of heat stress due to the lower heat production upon digestion and metabolism of fat compared with those of carbohydrates and proteins (Smith et al. 1978). However, the type of supplemented fat is another factor in this respect, as illustrated in the present work. Greater PUFA supplementation negatively influenced the production parameters at the current work, and these results are in agreement with the results of Seifi et al. (2018), who reported greater weight gain and feed intake along with a better FCR in heat-stressed broilers $\left(36^{\circ} \mathrm{C}\right)$ fed more SFA sources (coconut oil and tallow) compared with those of more USFA sources (olive and soy oil).

The presence of genistein, particularly with greater doses in the diet of heat-stressed quail, positively influenced the production parameters at the present work. Improved feed intake, weight gain, and FCR were also reported in broilers (Kamboh et al. 2013) and quail Onderci et al. (2004) reared under HS and supplemented with various levels of genistein. In accord with the productive performance parameters, increasing genistein supplementation also linearly decreased serum and thigh meat MDA concentrations in quail at the present work. Similar to the results of the current work, serum MDA concentrations were also found decreased in heat-stressed $\left(34^{\circ} \mathrm{C}\right)$ quail supplemented with 200,400 , or $800 \mathrm{mg}$ of genistein per kg of diet (Onderci et al. 2004$)$. These results were expected because genistein is a potent antioxidant Kładna et al. (2016) which linearly increased in serum and thigh muscle upon supplementing increasing amounts in the diet. Heat stress caused lower genistein concentrations in both serum and thigh meat tissues. These results could imply that some of the genistein supplemented to heat-stressed quail were used in antioxidant, cytoprotective, anti-inflammatory, and antiapoptotic functions (Hegab et al. 2018; Xia et al. 2019), leaving less genistein amounts available to be stored in tissues. Greater amounts of genistein consumed by genistein-supplemented poultry meat, as shown in the present work, may serve as a protective agent against cancer, obesity, diabetes, Alzheimer's, and many more health problems (Chen et al. 2020; R. Li et al. 2020).

Tigh meat FA profiles of quail, whether reared under HS or TN, were generally reflections of those of supplemental FA profiles including 16:0, C18:1n-9, 18:2, ALA, EPA, DHA, and total PUFA at the present work with no regards to effects of genistein supplements. Similarly, dietary fatty acids accumulating in tissues of poultry were also reported by other researchers (Cortinas et al. 2004; Ribeiro et al. 2013; Sirri et al. 2003).

Greater content of oleic acid (18:1n9) and arachidonic acid (20:4n-6) in thigh muscle of quail supplemented with a low PUFA level (PUFA15) is desirable since arachidonic acid is an essential FA, and oleic acid is known as a health FA involving in improving insulin sensitivity Ryan et al. (2000), reducing LDLcholesterol but elevating HDL-cholesterol (Damasceno et al. 2011; Estévez-González et al. 2010). However, 18:2, ALA, EPA, DHA, total PUFA, total USFA, total n-3 PUFA, and total n-6 PUFA contents were greater in thigh muscle of quail supplemented with a high PUFA level (PUFA45). Therefore, not all but most beneficial FA were present in thigh meat of high PUFA-supplemented quail. Increased concentrations of 18:2 and ALA in poultry products provide, upon consumption, essential FA to humans. Similarly, greater EPA and DHA contents found in thigh meat of high PUFA-supplemented quail provide, upon consumption, more intake of these FA for humans. n-3 FA, particularly EPA and DHA, are associated with the prevention of several health problems, including cardiovascular diseases, immunity, Alzheimer's disease, weight gain, and many more (Elagizi et al. 2021; Miles et al. 2021; Simopoulos, 2008; Swanson et al. 2012). However, ALA, EPA, and DHA are not consumed with adequate amounts by most people, including Americans (Burnett et al. 2020). Therefore, increased amounts of these FA in poultry products is a good strategy to get the proper amounts shown in the present work. The low ratios of $n-6$ to n-3 PUFA have been linked to the prevention of certain diseases, including cancer, diabetes, and cardiovascular diseases (Simopoulos, 2006; Urlić et al. 2020). The low ratios were also in accord with greater concentrations of 18:2, ALA, EPA, DHA, total PUFA, total USFA, total n-3 PUFA, and total n-6 PUFA in thigh muscle of quail supplemented with high PUFA, supporting healthier poultry products for human consumption.

In an attempt to increase the PUFA content of chicken meat by supplementing a mix of fat sources, including fish oil, to the diet, the case at the present work should be evaluated with a precaution. Poultry meat rich in PUFA content is vulnerable to oxidation since USFA is the substrate for oxidation. The oxidation process causes alterations in flavor, color, and nutritional value in a negative way (Luna et al. 2010). Therefore, in this respect, the present work results regarding meat quality should be evaluated with a limitation.

The present work revealed that heat stress is a negative factor in the productive performance of quail. Although moderate PUFA supplementation supported a greater productive performance, high amounts of PUFA supplementation yielded healthier meat with greater concentrations of $n-3$ FA, including EPA and DHA. Genistein supplementation to quail provided greater productive performance and greater meat genistein concentrations with no influence on meat FA profile. In conclusion, genistein with greater doses along with greater PUFA inclusion to the diet of quail reared under heat stress is recommended for alleviating the adverse effects of heat stress and for yielding healthier meat for human consumption.

\section{Declarations}

Acknowledgments The authors thank the Veterinary Control and Research, Institute of Ministry of Agriculture, Elazig, Turkey, for providing the research facility. The authors also appreciate Dr. Okkeş Yilmaz and Dr. Mehmet Guvenc for their help in fatty acid analysis.

Author contribution Cemal Orhan and Nurhan Sahin were involved in the conception and design; Cemal Orhan performed the experiments and analyzed the samples; Cemal Orhan, and Nurhan Sahin performed the lab analyses; Cemal Orhan, Osman Kucuk and Kazim Sahin drafted the manuscript; Osman Kucuk, Cemal Orhan, Nurhan Sahin and Kazim Sahin wrote and revised the paper. All the authors read and approved the final version of the manuscript. All authors agree to be accountable for all aspects of the work. All authors reviewed the results and approved the final version of the manuscript.

Funding This work was supported by Firat University Scientific Research Projects Unit (No: FUBAP-1542) Elazig, Turkey.

Availability of data and material The data are available upon request.

Code availability The codes for analyses are available upon request. 
Ethics approval The experiment was conducted following animal welfare regulations at the Veterinary Control and Research Institute of Elazig, Turkey, with all procedures approved by the Institutional Animal Care and Use Committee.

Consent to participate Not applicable.

Consent for publication Not applicable.

Conflict of interest The authors declare no competing interests.

\section{References}

1. Alagawany, M., Elnesr, S.S., Farag, M.R., Abd El-Hack, M.E., Khafaga, A.F., Taha, A.E., Tiwari, R., Yatoo, M.I., Bhatt, P., Khurana, S.K., Dhama, K., 2019. Omega-3 and Omega-6 fatty acids in poultry nutrition: effect on production performance and health. Animals 9, 573. https://doi.org/10.3390/ani9080573

2. Alfthan, G., Eurola, M., Ekholm, P., Venäläinen, E.R., Root, T., Korkalainen, K., Hartikainen, H., Salminen, P., Hietaniemi, V., Aspila, P., Aro, A., 2015. Effects of nationwide addition of selenium to fertilizers on foods, and animal and human health in Finland: From deficiency to optimal selenium status of the population. Journal of Trace Elements in Medicine and Biology 31, 142-147. https://doi.org/10.1016/j.jtemb.2014.04.009

3. Attia, Y.A., Abd El-Hamid, A.E.-H.E., Abedalla, A.A., Berika, M.A., Al-Harthi, M.A., Kucuk, O., Sahin, K., Abou-Shehema, B.M., 2016. Laying performance, digestibility and plasma hormones in laying hens exposed to chronic heat stress as affected by betaine, vitamin $C$, and/or vitamin $E$ supplementation. SpringerPlus 5, 1619. https://doi.org/10.1186/s40064-016-3304-0

4. Barim, O., Karatepe, M., 2010. The effects of pollution on the vitamins A, E, C, $\beta$-carotene contents and oxidative stress of the freshwater crayfish, Astacus leptodactylus. Ecotoxicology and Environmental Safety 73, 138-142. https://doi.org/10.1016/j.ecoenv.2009.08.002

5. Burnett, D.D., Legako, J.F., Phelps, K.J., Gonzalez, J.M., 2020. Biology, strategies, and fresh meat consequences of manipulating the fatty acid composition of meat. Journal of Animal Science 98. https://doi.org/10.1093/jas/skaa033

6. Chen, X., Gu, J., Wu, Y., Liang, P., Shen, M., Xi, J., Qin, J., 2020. Clinical characteristics of colorectal cancer patients and anti-neoplasm activity of genistein. Biomedicine \& Pharmacotherapy 124, 109835. https://doi.org/10.1016/j.biopha.2020.109835

7. Cortinas, L., Villaverde, C., Galobart, J., Baucells, M.D., Codony, R., Barroeta, A.C., 2004. Fatty acid content in chicken thigh and breast as affected by dietary polyunsaturation level. Poultry Science 83, 1155-1164. https://doi.org/10.1093/ps/83.7.1155

8. D'Souza, N., Skonberg, D.I., Camire, M.E., Guthrie, K.E., Malison, J., Lima, L., 2005. Influence of dietary genistein levels on tissue genistein deposition and on the physical, chemical, and sensory quality of rainbow trout, Oncorhynchus mykiss. Journal of Agricultural and Food Chemistry 53, 36313636. https://doi.org/10.1021/jf0484024

9. Damasceno, N.R.T., Pérez-Heras, A., Serra, M., Cofán, M., Sala-Vila, A., Salas-Salvadó, J., Ros, E., 2011. Crossover study of diets enriched with virgin olive oil, walnuts or almonds. Effects on lipids and other cardiovascular risk markers. Nutrition, Metabolism and Cardiovascular Diseases 21, S14S20. https://doi.org/10.1016/j.numecd.2010.12.006

10. El-Kholy, M.S., El-Hindawy, M.M., Alagawany, M., Abd El-Hack, M.E., El-Sayed, S.A.E.-G.A.E.-H., 2017. Dietary supplementation of chromium can alleviate negative impacts of heat stress on performance, carcass yield, and some blood hematology and chemistry indices of growing Japanese quail. Biological Trace Element Research 179, 148-157. https://doi.org/10.1007/s12011-017-0936-z

11. Elagizi, A., Lavie, C.J., O’Keefe, E., Marshall, K., O’Keefe, J.H., Milani, R. V., 2021. An update on Omega-3 polyunsaturated fatty acids and cardiovascular health. Nutrients 13, 204. https://doi.org/10.3390/nu13010204

12. Estévez-González, M.D., Saavedra-Santana, P., López-Ríos, L., Chirino, R., Cebrero-García, E., Peña-Quintana, L., Betancor-León, P., 2010. HDL cholesterol levels in children with mild hypercholesterolemia: effect of consuming skim milk enriched with olive oil and modulation by the TAQ 1B polymorphism in the CETP gene. Annals of Nutrition and Metabolism 56, 288-293. https://doi.org/10.1159/000290405

13. Goel, A., 2021. Heat stress management in poultry. Journal of Animal Physiology and Animal Nutrition jpn.13496. https://doi.org/10.1111/jpn.13496

14. Gupta, S.K., Dongare, S., Mathur, R., Mohanty, I.R., Srivastava, S., Mathur, S., Nag, T.C., 2015. Genistein ameliorates cardiac inflammation and oxidative stress in streptozotocin-induced diabetic cardiomyopathy in rats. Molecular and Cellular Biochemistry 408, 63-72. https://doi.org/10.1007/s11010015-2483-2

15. Habashy, W.S., Milfort, M.C., Fuller, A.L., Attia, Y.A., Rekaya, R., Aggrey, S.E., 2017. Effect of heat stress on protein utilization and nutrient transporters in meat-type chickens. International Journal of Biometeorology 61, 2111-2118. https://doi.org/10.1007/s00484-017-1414-1

16. Hara, A., Radin, N.S., 1978. Lipid extraction of tissues with a low-toxicity solvent. Analytical Biochemistry 90, 420-426. https://doi.org/10.1016/00032697(78)90046-5

17. He, X., Lu, Z., Ma, B., Zhang, L., Li, J., Jiang, Y., Zhou, G., Gao, F., 2018. Effects of chronic heat exposure on growth performance, intestinal epithelial histology, appetite-related hormones and genes expression in broilers. Journal of the Science of Food and Agriculture 98, 4471-4478. https://doi.org/10.1002/jsfa.8971

18. Hegab, I.I., Abd-Ellatif, R.N., Sadek, M.T., 2018. The gastroprotective effect of N -acetylcysteine and genistein in indomethacin-induced gastric injury in rats. Canadian Journal of Physiology and Pharmacology 96, 1161-1170. https://doi.org/10.1139/cjpp-2017-0730

19. Kamboh, A.A., Hang, S.Q., Bakhetgul, M., Zhu, W.-Y., 2013. Effects of genistein and hesperidin on biomarkers of heat stress in broilers under persistent summer stress. Poultry Science 92, 2411-2418. https://doi.org/10.3382/ps.2012-02960

Page 6/13 
20. Kładna, A., Berczyński, P., Kruk, I., Piechowska, T., Aboul-Enein, H.Y., 2016. Studies on the antioxidant properties of some phytoestrogens. Luminescence 31, 1201-1206. https://doi.org/10.1002/bio.3091

21. Konieczka, P., Czauderna, M., Smulikowska, S., 2017. The enrichment of chicken meat with omega-3 fatty acids by dietary fish oil or its mixture with rapeseed or flaxseed-Effect of feeding duration. Animal Feed Science and Technology 223, 42-52. https://doi.org/10.1016/j.anifeedsci.2016.10.023

22. Li, Q., Wan, G., Peng, C., Xu, L., Yu, Y., Li, L., Li, G., 2020. Effect of probiotic supplementation on growth performance, intestinal morphology, barrier integrity, and inflammatory response in broilers subjected to cyclic heat stress. Animal Science Journal 91. https://doi.org/10.1111/asj.13433

23. Li, R., Ding, X.-W., Geetha, T., Al-Nakkash, L., Broderick, T.L., Babu, J.R., 2020. Beneficial effect of genistein on diabetes-induced brain damage in the ob/ob mouse model. Drug Design, Development and Therapy Volume 14, 3325-3336. https://doi.org/10.2147/DDDT.S249608

24. Luna, A., Lábaque, M.C., Zygadlo, J.A., Marin, R.H., 2010. Effects of thymol and carvacrol feed supplementation on lipid oxidation in broiler meat. Poultry Science 89, 366-370. https://doi.org/10.3382/ps.2009-00130

25. Manson, J.E., Cook, N.R., Lee, I.-M., Christen, W., Bassuk, S.S., Mora, S., Gibson, H., Gordon, D., Copeland, T., D’Agostino, D., Friedenberg, G., Ridge, C., Bubes, V., Giovannucci, E.L., Willett, W.C., Buring, J.E., 2019. Vitamin D supplements and prevention of cancer and cardiovascular disease. New England Journal of Medicine 380, 33-44. https://doi.org/10.1056/NEJMoa1809944

26. Mika, A., Kobiela, J., Pakiet, A., Czumaj, A., Sokołowska, E., Makarewicz, W., Chmielewski, M., Stepnowski, P., Marino-Gammazza, A., Sledzinski, T., 2020. Preferential uptake of polyunsaturated fatty acids by colorectal cancer cells. Scientific Reports 10, 1954. https://doi.org/10.1038/s41598-020-58895-7

27. Miles, E.A., Childs, C.E., Calder, P.C., 2021. Long-chain polyunsaturated fatty acids (LCPUFAs) and the developing immune system: a narrative review. Nutrients 13, 247. https://doi.org/10.3390/nu13010247

28. Nawab, A., Ibtisham, F., Li, G., Kieser, B., Wu, J., Liu, W., Zhao, Y., Nawab, Y., Li, K., Xiao, M., An, L., 2018. Heat stress in poultry production: Mitigation strategies to overcome the future challenges facing the global poultry industry. Journal of Thermal Biology 78, 131-139. https://doi.org/10.1016/j.jtherbio.2018.08.010

29. Onderci, M., Sahin, K., Sahin, N., Gursu, M., Doerge, D., Sarkar, F., Kucuk, O., 2004. The effect of genistein supplementation on performance and antioxidant status of Japanese quail under heat stress. Archives of Animal Nutrition 58, 463-471. https://doi.org/10.1080/00039420400020017

30. Orhan, C., Kucuk, O., Sahin, N., Tuzcu, M., Sahin, K., 2020. Effects of taurine supplementation on productive performance, nutrient digestibility and gene expression of nutrient transporters in quails reared under heat stress. Journal of Thermal Biology 92, 102668.

https://doi.org/10.1016/j.jtherbio.2020.102668

31. Orhan, C., Tuzcu, M., Deeh, P.B.D., Sahin, N., Komorowski, J.R., Sahin, K., 2019. Organic chromium form alleviates the detrimental effects of heat stress on nutrient digestibility and nutrient transporters in laying hens. Biological Trace Element Research 189, 529-537. https://doi.org/10.1007/s12011018-1485-9

32. Ratriyanto, A., Prastowo, S., 2019. Floor space and betaine supplementation alter the nutrient digestibility and performance of Japanese quail in a tropical environment. Journal of Thermal Biology 83, 80-86. https://doi.org/10.1016/j.jtherbio.2019.05.008

33. Ribeiro, T., Lordelo, M.M., Alves, S.P., Bessa, R.J.B., Costa, P., Lemos, J.P.C., Ferreira, L.M.A., Fontes, C.M.G.A., Prates, J.A.M., 2013. Direct supplementation of diet is the most efficient way of enriching broiler meat with n-3 long-chain polyunsaturated fatty acids. British Poultry Science 54 , 753-765. https://doi.org/10.1080/00071668.2013.841861

34. Roushdy, E.M., Zaglool, A.W., Hassan, F.A.M., 2020. Thermal stress consequences on growth performance, immunological response, antioxidant status, and profitability of finishing broilers: transcriptomic profile change of stress-related genes. Tropical Animal Health and Production 52, 36853696. https://doi.org/10.1007/s11250-020-02405-4

35. Ryan, M., Mcinerney, D., Owens, D., Collins, P., Johnson, A., Tomkin, G.H., 2000. Diabetes and the Mediterranean diet: A beneficial effect of oleic acid on insulin sensitivity, adipocyte glucose transport and endothelium-dependent vasoreactivity. QJM - Monthly Journal of the Association of Physicians 93, 85-91. https://doi.org/10.1093/qjmed/93.2.85

36. Sahin, K., Orhan, C., Tuzcu, M., Sahin, N., Hayirli, A., Bilgili, S., Kucuk, O., 2016. Lycopene activates antioxidant enzymes and nuclear transcription factor systems in heat-stressed broilers. Poultry Science 95, 1088-1095. https://doi.org/10.3382/ps/pew012

37. Sahin, N., Tuzcu, M., Orhan, C., Onderci, M., Eroksuz, Y., Sahin, K., 2009. The effects of vitamin C and E supplementation on heat shock protein 70 response of ovary and brain in heat-stressed quail. British Poultry Science 50, 259-265. https://doi.org/10.1080/00071660902758981

38. Sahin, K., Kucuk, O., 2003. Zinc supplementation alleviates heat stress in laying Japanese quail. The Journal of nutrition, 133(9), $2808-2811$. https://doi.org/10.1093/jn/133.9.2808

39. Sanaei, M., Kavoosi, F., Valiani, A., Ghobadifar, M., 2018. Effect of genistein on apoptosis and proliferation of hepatocellular Carcinoma Hepa1-6 Cell Line. International Journal of Preventive Medicine 9, 12. https://doi.org/10.4103/ijpvm.IJPVM_249_16

40. SAS, 2004. SAS/STAT 9.1 User's Guide.

41. Seifi, K., Rezaei, M., Yansari, A.T., Riazi, G.H., Zamiri, M.J., Heidari, R., 2018. Saturated fatty acids may ameliorate environmental heat stress in broiler birds by affecting mitochondrial energetics and related genes. Journal of Thermal Biology 78, 1-9. https://doi.org/10.1016/j.jtherbio.2018.08.018

42. Shang, X.G., Wang, F.L., Li, D.F., Yin, J.D., Li, J.Y., 2004. Effects of dietary conjugated linoleic acid on the productivity of laying hens and egg quality during refrigerated storage. Poultry Science 83, 1688-1695. https://doi.org/10.1093/ps/83.10.1688

43. Simopoulos, A.P., 2008. The importance of the Omega-6/Omega-3 fatty acid ratio in cardiovascular disease and other chronic diseases. Experimental Biology and Medicine 233, 674-688. https://doi.org/10.3181/0711-MR-311 
44. Simopoulos, A.P., 2006. Evolutionary aspects of diet, the omega-6/omega-3 ratio and genetic variation: nutritional implications for chronic diseases. Biomedicine \& Pharmacotherapy 60, 502-507. https://doi.org/10.1016/j.biopha.2006.07.080

45. Sirri, F., Tallarico, N., Meluzzi, A., Franchini, A., 2003. Fatty acid composition and productive traits of broiler fed diets containing conjugated linoleic acid. Poultry Science 82, 1356-1361. https://doi.org/10.1093/ps/82.8.1356

46. Smith, R.R., Rumsey, G.L., Scott, M.L., 1978. Heat increment associated with dietary protein, fat, carbohydrate and complete diets in salmonids comparative energetic efficiency. The Journal of Nutrition 108, 1025-1032. https://doi.org/10.1093/jn/108.6.1025

47. Sohail, M.U., Rahman, Z.U., ljaz, A., Yousaf, M.S., Ashraf, K., Yaqub, T., Zaneb, H., Anwar, H., Rehman, H., 2011. Single or combined effects of mannanoligosaccharides and probiotic supplements on the total oxidants, total antioxidants, enzymatic antioxidants, liver enzymes, and serum trace minerals in cyclic heat-stressed broilers. Poultry Science 90, 2573-2577. https://doi.org/10.3382/ps.2011-01502

48. Song, J., Xiao, K., Ke, Y.L., Jiao, L.F., Hu, C.H., Diao, Q.Y., Shi, B., Zou, X.T., 2014. Effect of a probiotic mixture on intestinal microflora, morphology, and barrier integrity of broilers subjected to heat stress. Poultry Science 93, 581-588. https://doi.org/10.3382/ps.2013-03455

49. Swanson, D., Block, R., Mousa, S.A., 2012. Omega-3 fatty acids EPA and DHA: health benefits throughout life. Advances in Nutrition 3, $1-7$. https://doi.org/10.3945/an.111.000893

50. Tacyildiz, N., Ozyoruk, D., Yavuz, G., Unal, E., Dincaslan, H., Dogu, F., Sahin, K., Kucuk, O., 2010. Soy isoflavones ameliorate the adverse effects of chemotherapy in children. Nutrition and Cancer 62, 1001-1005. https://doi.org/10.1080/01635581.2010.509841

51. Urlić, M., Urlić, I., Urlić, H., Mašek, T., Benzon, B., Vitlov Uljević, M., Vukojević, K., Filipović, N., 2020. Effects of different n6/n3 PUFAs dietary ratio on cardiac diabetic neuropathy. Nutrients 12, 2761. https://doi.org/10.3390/nu12092761

52. Ustundag, B., Bahcecioglu, I.H., Sahin, K., Duzgun, S., Koca, S., Gulcu, F., Ozercan, I.H., 2007. Protective effect of soy isoflavones and activity levels of plasma paraoxonase and arylesterase in the experimental nonalcoholic steatohepatitis model. Digestive Diseases and Sciences 52, $2006-2014$. https://doi.org/10.1007/s10620-006-9251-9

53. Wu, Y.B., Li, L., Wen, Z.G., Yan, H.J., Yang, P.L., Tang, J., Xie, M., Hou, S.S., 2019. Dual functions of eicosapentaenoic acid-rich microalgae: enrichment of yolk with n-3 polyunsaturated fatty acids and partial replacement for soybean meal in diet of laying hens. Poultry Science 98, $350-357$.

https://doi.org/10.3382/ps/pey372

54. Xia, S., Wang, J., Kalionis, B., Zhang, W., Zhao, Y., 2019. Genistein protects against acute pancreatitis via activation of an apoptotic pathway mediated through endoplasmic reticulum stress in rats. Biochemical and Biophysical Research Communications 509, 421-428.

https://doi.org/10.1016/j.bbrc.2018.12.108

\section{Tables}

Table 1 Ingredients and nutrient contents of the basal diet fed to quail, dry matter basis

\begin{tabular}{ll} 
Ingredient & $\%$ \\
\hline Wheat & 39.47 \\
\hline Soybean meal, 48\% CP & 34.01 \\
\hline Barley & 13.30 \\
\hline Added oil ${ }^{1}$ & 9.00 \\
\hline Dicalcium phosphate & 2.00 \\
\hline Calcium carbonate & 1.0 \\
\hline Vitamin-mineral mix ${ }^{2}$ & 0.50 \\
\hline Sodium chloride & 0.40 \\
\hline DL-Methionine & 0.28 \\
\hline L-Lysine & 0.04 \\
\hline Nutrient Analyses & \\
\hline ME, kcal/kg & 3200 \\
\hline Crude protein, \% & 22.96 \\
\hline Ether extract, \% & 10.75 \\
\hline Crude fiber, \% & 3.61 \\
\hline Ash content, \% & 5.83 \\
\hline Genistein, mg/kg & 107.26 \\
\hline
\end{tabular}


${ }^{1}$ The basal diet contained $9 \%$ added fat with different sources as either $90 \mathrm{~g}$ tallow/ $\mathrm{kg}$ diet as PUFA15 or a combination of $35 \mathrm{~g}$ tallow/ $\mathrm{kg}$ diet, $45 \mathrm{~g}$ linseed oil/kg diet and $10 \mathrm{~g}$ fish oil/kg diet as PUFA45.

${ }^{2}$ Vitamin premix provides the following per kilogram: all-trans- retinyl acetate, $1.8 \mathrm{mg}$; cholecalciferol, $0.025 \mathrm{mg}$; all-rac-a-tocopherol acetate, $1.25 \mathrm{mg}$; menadione (menadione sodium bisulphate, $1.1 \mathrm{mg}$; riboflavin, 4, $4 \mathrm{mg}$; thiamine (thiamine mononitrate), $1.1 \mathrm{mg}$; pyridoxine, $2.2 \mathrm{mg}$; niacin, $35 \mathrm{mg}$; Capantothenate, $10 \mathrm{mg}$; vitamin B12, $0.02 \mathrm{mg}$; folic acid, $0.55 \mathrm{mg}$; d-biotin, $0.1 \mathrm{mg}$. Mineral premix provides the following per kilogram: Mn (from MnO), 40 mg; Fe (from FeSO4), 12.5 mg; Zn (from ZnO), 25 mg; Cu (from CuSO4), 3.5 mg; I (from KI) , 0.3 mg; Se (from NaSe) , 0.15 mg; choline chloride, 175 mg.

${ }^{3}$ Analyzed by HPLC.

Table 2 Fatty acids profiles (g/100 g total fat) of PUFA15 and PUFA45 of diets

\begin{tabular}{lll} 
Fatty acid & PUFA15 & PUFA45 \\
\hline C10:0 & 0.05 & 0.02 \\
\hline C14:0 & 2.78 & 1.82 \\
\hline C15:0 & 0.45 & 0.23 \\
\hline C16:0 & 24.29 & 15.51 \\
\hline C17:0 & 1.21 & 0.54 \\
\hline C18:0 & 14.94 & 7.81 \\
\hline C20:0 & 0.12 & 0.17 \\
\hline Total SFA & 43.84 & 26.10 \\
\hline C16:1n-9 & 0.20 & 0.12 \\
\hline C16:1n-7 & 2.30 & 1.68 \\
\hline C18:1n-9 & 36.35 & 23.99 \\
\hline C18:1n-7 & 1.63 & 1.31 \\
\hline C20:1 & 0.29 & 0.32 \\
\hline C24:1 & 0.09 & 0.82 \\
\hline Total MUFA & 40.86 & 28.24 \\
\hline C18:2n-6 & 13.43 & 18.28 \\
\hline C18:3n-3 (ALA) & 1.58 & 25.03 \\
\hline C18:4 & 0.29 & 0.24 \\
\hline C20:4n-6 & -- & 0.13 \\
\hline C20:5n-3 (EPA) & -- & 1.80 \\
\hline C22:6n-3 (DHA) & -- & 0.18 \\
\hline Total PUFA & 15.30 & 45.66 \\
\hline PUFA:SFA & 0.35 & 1.75 \\
\hline
\end{tabular}

SFA: Saturated fatty acids; MUFA: Monounsaturated fatty acids; PUFA: Polyunsaturated fatty acids; ALA: Alpha-Linolenic acid; EPA: Eicosapentaenoic acid; DHA: Docosahexaenoic acid.

Table 3 Effects of dietary supplementation of polyunsaturated fatty acid and genistein on performance in quail reared under different environmental temperatures 


\begin{tabular}{|c|c|c|c|c|c|c|c|}
\hline ET & $\begin{array}{l}\text { PUFA Level } \\
(\%)\end{array}$ & $\begin{array}{l}\text { Genistein Level } \\
(\mathrm{mg} / \mathrm{kg})\end{array}$ & $\begin{array}{l}\text { Initial } \\
\text { BW (g) }\end{array}$ & $\begin{array}{l}\text { Final } \\
\text { BW }(g)^{1}\end{array}$ & $\begin{array}{l}\text { BW } \\
\text { Gain }(g)^{1}\end{array}$ & $\begin{array}{l}\text { Cumulative } \\
\mathrm{FI}(\mathrm{g})^{2}\end{array}$ & $\begin{array}{l}\text { FCR } \\
(g / g)^{1,3}\end{array}$ \\
\hline \multirow[t]{6}{*}{ TN } & \multirow{3}{*}{15} & 0 & 32.93 & 187.37 & 154.43 & 721.00 & 4.67 \\
\hline & & 400 & 33.00 & 186.10 & 153.10 & 704.80 & 4.60 \\
\hline & & 800 & 33.77 & 187.97 & 154.20 & 709.20 & 4.60 \\
\hline & \multirow{3}{*}{45} & 0 & 32.87 & 183.10 & 150.23 & 707.20 & 4.71 \\
\hline & & 400 & 32.10 & 182.96 & 150.86 & 705.40 & 4.68 \\
\hline & & 800 & 32.97 & 184.20 & 151.23 & 702.00 & 4.64 \\
\hline \multirow[t]{6}{*}{ HS } & \multirow{3}{*}{15} & 0 & 32.23 & 165.27 & 133.04 & 657.80 & 4.94 \\
\hline & & 400 & 32.90 & 170.47 & 137.57 & 661.40 & 4.81 \\
\hline & & 800 & 33.07 & 171.37 & 138.30 & 659.80 & 4.77 \\
\hline & \multirow{3}{*}{45} & 0 & 33.03 & 162.07 & 129.04 & 645.80 & 5.00 \\
\hline & & 400 & 32.97 & 166.07 & 133.10 & 657.60 & 4.94 \\
\hline & & 800 & 32.53 & 168.10 & 135.57 & 660.20 & 4.87 \\
\hline \multicolumn{3}{|c|}{ SEM } & 0.37 & 0.69 & 0.63 & 4.01 & 0.02 \\
\hline \multicolumn{3}{|c|}{ ANOVA } & \multicolumn{5}{|c|}{$-p<-$} \\
\hline \multicolumn{3}{|l|}{ ET } & 0.53 & 0.001 & 0.001 & 0.001 & 0.001 \\
\hline \multicolumn{3}{|c|}{ PUFA } & 0.55 & 0.001 & 0.001 & 0.01 & 0.001 \\
\hline \multicolumn{3}{|l|}{ GN } & 0.08 & 0.001 & 0.001 & 0.97 & 0.001 \\
\hline \multicolumn{3}{|c|}{ ET x PUFA } & 0.11 & 0.90 & 0.41 & 0.72 & 0.07 \\
\hline \multicolumn{3}{|c|}{$\mathrm{ET} \times \mathrm{GN}$} & 0.10 & 0.001 & 0.001 & 0.006 & 0.001 \\
\hline \multicolumn{3}{|c|}{ PUFA x GN } & 0.71 & 0.001 & 0.001 & 0.11 & 0.001 \\
\hline \multicolumn{3}{|c|}{ ET x PUFA x GN } & 0.04 & 0.69 & 0.29 & 0.58 & 0.71 \\
\hline
\end{tabular}

ET: Environmental temperature; TN: Thermoneutral; HS: Heat Stress; PUFA: Polyunsaturated fatty acids; GN: Genistein level; BW: Body weight; Fl: Feed intake; FCR: Feed conversion ratio; ${ }^{1}$ Linear effect of supplemental genistein, $p<0.001$.

${ }^{2}$ Cumulative feed intake.

${ }^{3}$ Feed conversion ratio (feed intake/BW gain, $\mathrm{g} / \mathrm{g}$ ).

Table 4 Effects of dietary supplementation of polyunsaturated fatty acid and genistein on thigh muscle fatty acid profile ( $\mathrm{g} / 100 \mathrm{~g}$ fat) in quail reared under different environmental temperatures $(n=10)$ 


\section{PUFA15}

PUFA45

Genistein Level

PUFA15

Genistein Level

Genistein Level

\begin{tabular}{|c|c|c|c|c|c|c|c|c|c|c|c|c|c|c|c|c|}
\hline & 0 & 400 & 800 & 0 & 400 & 800 & 0 & 400 & 800 & 0 & 400 & 800 & & ET & PUFA & $\mathrm{GN}$ \\
\hline C14:0 & 2.07 & 2.18 & 2.13 & 1.44 & 1.51 & 1.48 & 2.01 & 1.82 & 2.04 & 1.30 & 1.36 & 1.34 & 0.10 & 0.006 & 0.001 & 0.80 \\
\hline
\end{tabular}

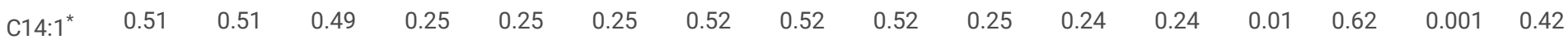

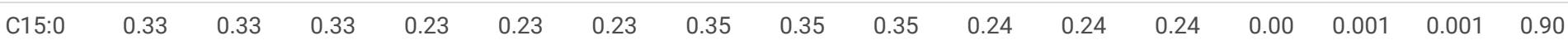

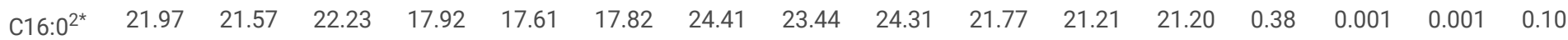

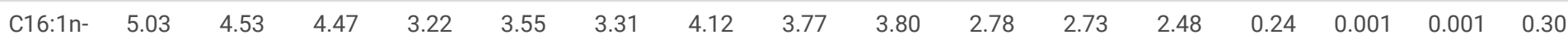
9

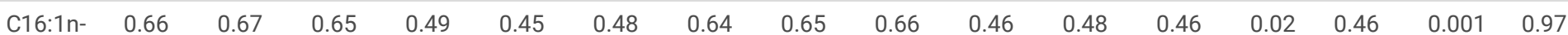

C17:0

$\begin{array}{llllllllllllllll}0.67 & 0.68 & 0.69 & 0.47 & 0.47 & 0.47 & 0.68 & 0.73 & 0.75 & 0.49 & 0.49 & 0.49 & 0.02 & 0.001 & 0.001 & 0.17\end{array}$

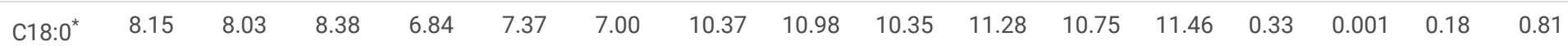

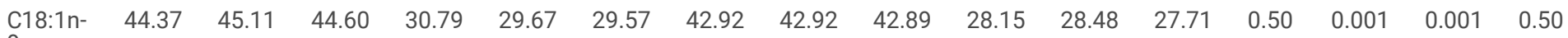

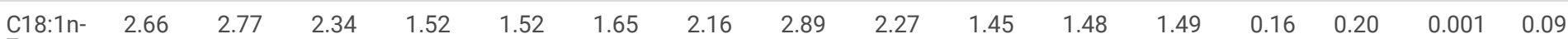

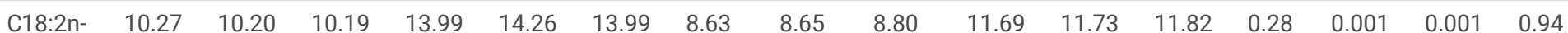
$6^{*}$

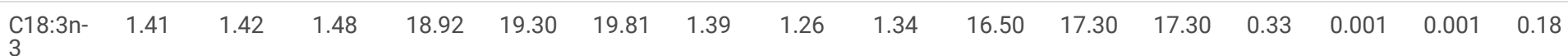
$(\mathrm{ALA})^{*}$

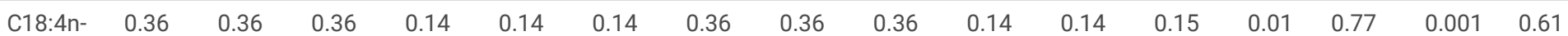

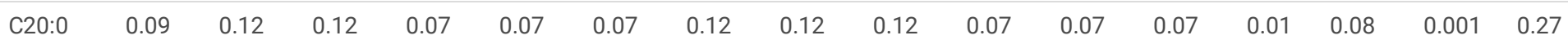

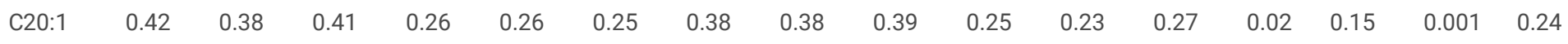

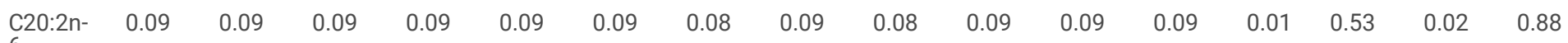
6

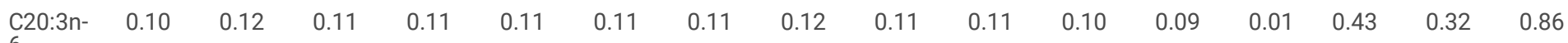
6

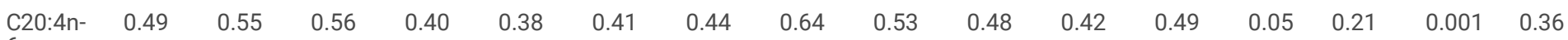
6

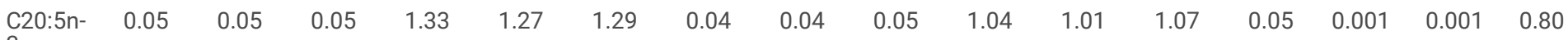
$(\mathrm{EPA})^{*}$

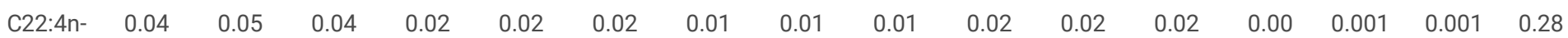
$6^{*}$

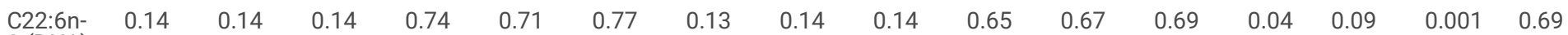
3 (DHA)

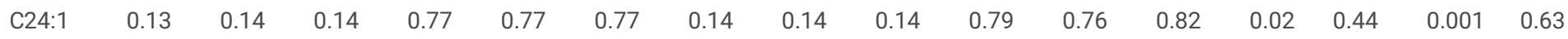

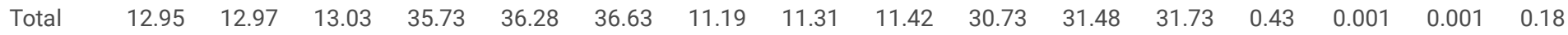
PUFA $^{*}$

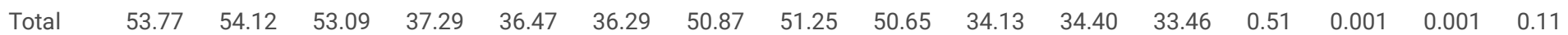

MUFA

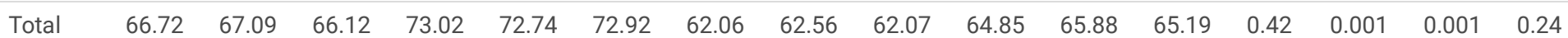
USFA $^{*}$

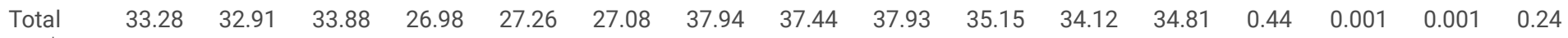
SFA*

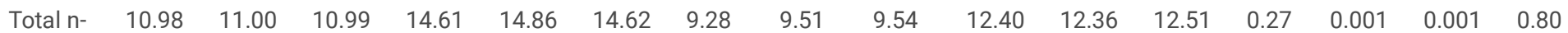
6 PUFA*

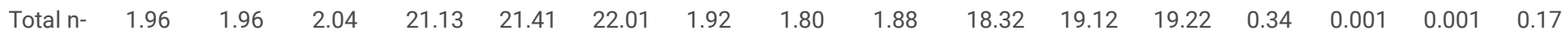


3 PUFA $^{*}$

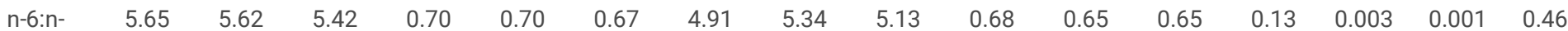

3 PUFA*

${ }^{1}$ ET: Environmental temperature; TN: Thermoneutral; HS: Heat Stress; GN: Genistein level; ALA: Alpha-Linolenic acid; EPA: Eicosapentaenoic acid; DHA: Docosahexaenoic acid; MUFA: Monounsaturated fatty acids; PUFA: Polyunsaturated fatty acids; USFA: Unsaturated fatty acids; SFA: Saturated fatty acids.

${ }^{2}$ Quadratic effect of supplemental genistein, $p<0,05$.

*ET x PUFA interactions, $p<0.05$

Total SFA include C14:0, C15:0, C16:0, C17:0, C18:0 and C20:0.

Total MUFA include C14:1, C16:1n-9, C16:1n-7, C18:1n-9, C18:1n-7, C20:1 and C24:1.

Total PUFA include C18:2n-6, C18:3n-3 (ALA), C18:4n-3, C20:2n-6, C20:3n-6, C20:4n-6, C20:5n-3 (EPA), C22:4n-6 and C22:6n-3 (DHA).

Total USFA includes total MUFA + total PUFA.

Total n-6 PUFA include C18:2n-6, C20:2n-6, C20:3n-6, C20:4n-6, and C22:4n-6.

Total n-3 PUFA include C18:3n-3 (ALA), C18:4n-3, C20:5n-3 (EPA), and C22:6n-3 (DHA).

Table 5 Effects of dietary supplementation of polyunsaturated fatty acid and genistein on serum metabolites ( $\mu \mathrm{g} / \mathrm{ml})$ in quail reared under different environmental temperatures $(n=10)$

\begin{tabular}{|c|c|c|c|c|c|c|c|}
\hline ET & $\begin{array}{l}\text { PUFA Level } \\
(\%)\end{array}$ & $\begin{array}{l}\text { Genistein Level } \\
(\mathrm{mg} / \mathrm{kg})\end{array}$ & $\mathrm{MDA}^{1}$ & Genistein $^{1}$ & Vitamin C & Vitamin E & Vitamin A \\
\hline \multirow[t]{6}{*}{ TN } & \multirow{3}{*}{15} & 0 & 0.06 & 0.12 & 8.33 & 1.69 & 1.36 \\
\hline & & 400 & 0.06 & 0.77 & 8.36 & 1.70 & 1.36 \\
\hline & & 800 & 0.05 & 1.61 & 8.39 & 1.73 & 1.37 \\
\hline & \multirow{3}{*}{45} & 0 & 0.07 & 0.12 & 8.49 & 1.69 & 1.34 \\
\hline & & 400 & 0.06 & 0.69 & 8.45 & 1.68 & 1.36 \\
\hline & & 800 & 0.06 & 1.59 & 8.52 & 1.69 & 1.35 \\
\hline \multirow[t]{6}{*}{ HS } & \multirow{3}{*}{15} & 0 & 0.10 & 0.10 & 5.35 & 1.11 & 1.01 \\
\hline & & 400 & 0.09 & 0.50 & 5.25 & 1.10 & 1.01 \\
\hline & & 800 & 0.08 & 1.11 & 5.71 & 1.13 & 1.01 \\
\hline & \multirow{3}{*}{45} & 0 & 0.14 & 0.10 & 4.62 & 1.07 & 0.99 \\
\hline & & 400 & 0.11 & 0.39 & 4.63 & 1.08 & 1.00 \\
\hline & & 800 & 0.10 & 0.99 & 5.05 & 1.09 & 1.00 \\
\hline \multicolumn{3}{|c|}{ SEM } & 0.003 & 0.05 & 0.35 & 0.11 & 0.06 \\
\hline \multicolumn{3}{|c|}{ ANOVA } & \multicolumn{5}{|c|}{$\longrightarrow$} \\
\hline \multicolumn{3}{|l|}{ ET } & 0.001 & 0.001 & 0.001 & 0.001 & 0.001 \\
\hline \multicolumn{3}{|c|}{ PUFA } & 0.001 & 0.04 & 0.19 & 0.67 & 0.74 \\
\hline \multicolumn{3}{|l|}{ GN } & 0.001 & 0.001 & 0.56 & 0.96 & 0.98 \\
\hline \multicolumn{3}{|c|}{ ET x PUFA } & 0.001 & 0.42 & 0.06 & 0.92 & 0.99 \\
\hline \multicolumn{3}{|c|}{$\mathrm{ET} \times \mathrm{GN}$} & 0.001 & 0.001 & 0.69 & 0.99 & 0.99 \\
\hline \multicolumn{3}{|c|}{ PUFA x GN } & 0.01 & 0.39 & 0.99 & 0.99 & 0.98 \\
\hline \multicolumn{3}{|c|}{ ET $x$ PUFA $x$ GN } & 0.08 & 0.81 & 0.98 & 0.99 & 0.98 \\
\hline
\end{tabular}

ET: Environmental temperature; TN: Thermoneutral; HS: Heat Stress; PUFA: Polyunsaturated fatty acids; GN: Genistein level 
${ }^{1}$ Linear effect of supplemental genistein, $p<0.001$.

Table 6 Effects of dietary supplementation of polyunsaturated fatty acid and genistein on thigh muscle metabolites ( $\mu \mathrm{g} / \mathrm{g}$ ) in quail reared under different environmental temperatures $(n=10)$

\begin{tabular}{|c|c|c|c|c|c|c|}
\hline ET & $\begin{array}{l}\text { PUFA Level } \\
(\%)\end{array}$ & $\begin{array}{l}\text { Genistein Level } \\
(\mathrm{mg} / \mathrm{kg})\end{array}$ & $\mathrm{MDA}^{1}$ & Genistein $^{1}$ & Vitamin E & Vitamin A \\
\hline \multirow[t]{6}{*}{ TN } & \multirow{3}{*}{15} & 0 & 0.46 & 0.21 & 4.52 & 2.83 \\
\hline & & 400 & 0.42 & 0.50 & 4.55 & 2.84 \\
\hline & & 800 & 0.40 & 0.79 & 4.54 & 2.98 \\
\hline & \multirow{3}{*}{45} & 0 & 0.56 & 0.21 & 4.50 & 2.73 \\
\hline & & 400 & 0.55 & 0.49 & 4.52 & 2.76 \\
\hline & & 800 & 0.52 & 0.78 & 4.53 & 2.79 \\
\hline \multirow[t]{6}{*}{ HS } & \multirow{3}{*}{15} & 0 & 1.21 & 0.10 & 2.15 & 1.55 \\
\hline & & 400 & 1.12 & 0.31 & 2.21 & 1.56 \\
\hline & & 800 & 1.08 & 0.47 & 2.24 & 1.56 \\
\hline & \multirow{3}{*}{45} & 0 & 1.39 & 0.10 & 2.11 & 1.54 \\
\hline & & 400 & 1.25 & 0.29 & 2.11 & 1.54 \\
\hline & & 800 & 1.22 & 0.46 & 2.13 & 1.54 \\
\hline \multicolumn{3}{|c|}{ SEM } & 0.02 & 0.02 & 0.25 & 0.22 \\
\hline \multicolumn{3}{|c|}{ ANOVA } & \multicolumn{4}{|c|}{$-{ }_{-}$} \\
\hline \multicolumn{3}{|l|}{ ET } & 0.001 & 0.001 & 0.001 & 0.001 \\
\hline \multicolumn{3}{|c|}{ PUFA } & 0.001 & 0.49 & 0.71 & 0.60 \\
\hline \multicolumn{3}{|l|}{ GN } & 0.001 & 0.001 & 0.98 & 0.93 \\
\hline \multicolumn{3}{|c|}{ ET x PUFA } & 0.15 & 0.95 & 0.83 & 0.68 \\
\hline \multicolumn{3}{|c|}{$\mathrm{ET} \times \mathrm{GN}$} & 0.004 & 0.001 & 0.99 & 0.95 \\
\hline \multicolumn{3}{|c|}{ PUFA x GN } & 0.92 & 0.95 & 0.99 & 0.98 \\
\hline \multicolumn{3}{|c|}{ ET x PUFA x GN } & 0.37 & 0.99 & 0.99 & 0.98 \\
\hline
\end{tabular}

ET: Environmental temperature; TN: Thermoneutral; HS: Heat Stress; PUFA: Polyunsaturated fatty acids; GN: Genistein level ${ }^{1}$ Linear effect of supplemental genistein, $p<0.001$. 